\title{
Contributions of lower extremity kinematics to trunk accelerations during moderate treadmill running
}

Timothy R Lindsay ${ }^{1 *}$, James A Yaggie ${ }^{2}$ and Stephen J McGregor ${ }^{1}$

\begin{abstract}
Background: Trunk accelerations during running provide useful information about movement economy and injury risk. However, there is a lack of data regarding the key biomechanical contributors to these accelerations. The purpose was to establish the biomechanical variables associated with root mean square (RMS) accelerations of the trunk.

Methods: Eighteen healthy males $(24.0 \pm 4.2 \mathrm{yr} ; 1.78 \pm 0.07 \mathrm{~m} ; 79.7 \pm 14.8 \mathrm{~kg})$ performed treadmill running with high resolution accelerometer measurement at the lumbar spine and full-body optical motion capture. We collected $60 \mathrm{sec}$ of data at three speeds $\left(2.22,2.78,3.33 \mathrm{~m} \cdot \mathrm{s}^{-1}\right)$. RMS was calculated for medio-lateral (ML), anterio-posterior (AP), vertical (VT), and the resultant Euclidean scalar (RES) acceleration. From motion capture, we calculated 14 kinematic variables, including mean sagittal plane joint angles at foot contact, mid-stance, and toe-off. Principal components analysis (PCA) was used to form independent components comprised of combinations of the original variables. Stepwise regressions were performed on the original variables and the components to determine contributions to RMS acceleration in each axis.
\end{abstract}

Results: Significant speed effects were found for RMS-accelerations in all axes $(p<0.05)$. Regressions of the original variables indicated from 4 to 5 variables associated with accelerations in each axis $\left(R^{2}=0.71\right.$ to $\left.0.82, p<0.001\right)$. The most prominent contributing variables were associated with the late flight and early stance phase. PCA reduced the data into four components. Component 1 included all hip angles before mid-stance and component 2 was primarily associated with propulsion. Regressions indicated key contributions from components 1 and 2 to ML, $V T$, and RES acceleration $(p<0.05)$.

Conclusions: The variables with highest contribution were prior to mid-stance and mechanically relate to shock absorption and attenuation of peak forces. Trunk acceleration magnitude is associated with global running variables, ranging from energy expenditure to forces lending to the mechanics of injury. These data begin to delineate running gait events and offer relationships of running mechanics to those structures more proximal in the kinetic chain. These relationships may provide insight for technique modification to maximize running economy or prevent injury.

Keywords: High resolution accelerometers, Root mean square, Principal components analysis, Running, Economy, Injury, Stiffness

\footnotetext{
* Correspondence: tlindsa2@emich.edu

${ }^{1}$ School of Health Promotion \& Human Performance, Eastern Michigan University, Ypsilanti, MI, USA

Full list of author information is available at the end of the article
} 


\section{Background}

Running is an increasingly popular sport that provides substantial health benefits at minimal expense. Estimates from 2011 are that 38.7 million Americans participate in running or jogging 6 or more days per year (up from 24.5 million in 2001), with 9.2 million doing so 110 or more days per year (up from 6.8 million in 2001) [1]. Offsetting the numerous health benefits of exercise is the relatively high incidence of injury, which according to one systematic review, ranges from 19-79\% [2]. Even at the lower end of this range, the high participation rate means that injury is a substantial concern. Since most running injuries are chronic rather than acute $[3,4]$, the tolerable level of accumulated stress is an important consideration. This stress depends on multiple factors including the training dose, anatomical structure, and movement mechanics [4-7]. We focus on mechanics in this paper.

Mechanically speaking, running involves the application of force to the ground to generate the resultant ground reaction force (GRF) necessary for forward propulsion and support against gravity. This places stress on soft tissue and bone via force transmission through the kinetic chain, which may lead to future injury if the exercise dosage exceeds regenerative capacity. A comprehensive description of forces requires a complicated model, but the acceleration of the center of mass (COM) can provide a simple quantification of net force. Continuous COM data may then be expressed as a root mean square (RMS) value to represent the overall magnitude of acceleration over many strides [8]. RMS provides a measure of dispersion similar to standard deviation, only relative to zero rather than the mean [9]. The presence of more extreme values in the signal (i.e., high acceleration or deceleration) increases the RMS value. Acceleration at any anatomical location depends on the level of attenuation through tissue deformation and joint excursion at all points distal. The attenuation of force and acceleration can be modified with lower limb stiffness and may alter the likelihood of running-related injuries [10,11]. High stiffness may aid performance and economy but also may increase the risk of injury to structural components. In contrast, stiffness that is too low may be metabolically costly and increase the risk of soft tissue injury [8,10-12]. Stiffness depends on the intrinsic properties of bone and soft tissue (muscle, tendon, ligament, and cartilage) [13], but also may be modified via kinematic changes. For example, in subjects instructed to perform a soft drop landing, there was greater knee joint excursion $[14,15]$. As well, Derrick [11] has argued that runners generally run with extended knees prior to impact, but are able to increase knee flexion in order to reduce vertical accelerations. Similarly, subjects who were instructed to adopt a "Groucho running" style had longer strides (believed to be associated with decreased stiffness) and decreased stiffness, as directly measured [16]. Interventions such as gait retraining to pursue this objective are promising and demonstrate that kinematics are modifiable $[17,18]$.

There has not yet been a direct investigation into the relationship between running mechanics and RMS acceleration. The measurement of acceleration requires little equipment, can be done in the field, and real-time feedback is possible. Since the major movements of running are in the sagittal plane, we focused on the flexion/extension behavior of the hip, knee, and ankle joints during various gait events, as well as some other key variables that are readily modifiable. The purpose of this study was to determine the biomechanical factors contributing to global axial accelerations in active healthy males. In previous work [8], we observed greater accelerations in healthy untrained runners compared to trained collegiate runners. In the current study we selected a sample that was relatively heterogeneous with regard to chosen mode of physical activity and indicative of those from the general population who might take up running as a recreational activity for health benefits. These individuals would be more likely to exhibit mechanics that would make them more susceptible to injury due to relatively high accelerations [8]. To accomplish our objectives, we used a multiple regression approach to determine the variables that best fit a least squares model generated for RMS acceleration in each axis. Additionally, principal components analysis (PCA) was used to establish potentially hidden interactions between individual variables that can be combined to form separate components. These components may be then assessed for their contribution to axial accelerations. Thus, with a view to performance and injury management, this study will provide a description of modifiable biomechanical factors and their relationship with RMS trunk accelerations.

\section{Methods}

\section{Subjects and experimental procedure}

Eighteen healthy, active, college-age males volunteered to participate. Subjects participated 2-7 times per week in various forms of physical activity such as individual endurance sports (including running for 6 subjects), strength training, team sports, and/or combat sports. The procedures of this study were approved by the Human Subjects Review Committee of Eastern Michigan University College of Health and Human Services. All subjects provided written informed consent.

We analyzed $60 \mathrm{sec}$ of data from three randomly-ordered treadmill run trials run at 2.22, 2.78, and $3.33 \mathrm{~m} \cdot \mathrm{s}^{-1}$. Subjects were given as much rest between trials as they desired (typically 60-180 s). Subject characteristics are presented in Table 1. 
Table 1 Subject characteristics

\begin{tabular}{lcccc}
\hline & Mean & SD & Min & Max \\
\hline Age $(\mathrm{yr})$ & 24.0 & 4.2 & 19 & 32 \\
Height $(\mathrm{m})$ & 1.78 & 0.07 & 1.66 & 1.89 \\
Mass $(\mathrm{kg})$ & 79.7 & 14.8 & 59.1 & 107.3 \\
BMl $\left(\mathrm{kg} \cdot \mathrm{m}^{-2}\right)$ & 25.2 & 3.6 & 20.8 & 31.7 \\
\hline
\end{tabular}

\section{Instrumentation}

We placed one triaxial high resolution accelerometer (G-Link ADXL 210, Microstrain, Inc., Williston, VT) on the dorsal mid-line, at the level of the iliac crest (approximately at the L4/L5 spinous process). Accelerometers mounted at this anatomical location can provide valid estimates of oxygen consumption during running and can distinguish mechanics between trained and untrained individuals [8]. Although the legs primarily move in the sagittal plane during running, this is not the case for the spine and pelvis. Because the accelerometer is mounted in that region, there is significant non-sagittal movement requiring measurement in three and not just two dimensions. The accelerometer (mass $=47 \mathrm{~g}$ ) consists of internal circuitry enclosed in a $58 \times 43 \times 21 \mathrm{~mm}$ casing, plus an antenna extending a bit outside the dimensions and adding $18 \mathrm{~mm}$ to the thickness. The accelerometer was mounted to a semi-rigid strap, and secured with elastic wrap to minimize extraneous movement of the device.

Kinematic data was collected with a 3-D optical motion capture system (Vicon MX, Vicon, Centennial, CO). We employed a 39-marker full body gait model (PlugIn-Gait, Vicon, Los Angeles, CA) consisting of 15 segments including the head, thorax, pelvis, upper arm, forearm, hand, thigh, shank, and foot. Seven cameras (Vicon T40 and T40 S) were placed roughly equidistant to the subject on the treadmill. Mean values for fourteen kinematic variables were calculated (mean value for left and right leg). Foot contact was defined as the point of lowest vertical displacement of the heel marker [19]. Mid-stance was defined as the lowest point of the software-estimated COM. Toe-off was defined as the point of maximum knee extension [19]. Lower limb joint angles were calculated according to the parameters of the software and model. Variables are listed and defined in Table 2.

\section{Data capture and analysis}

Data were collected in the medio-lateral (ML), anterioposterior (AP), and vertical (VT) axes. Trajectories were sampled at $200 \mathrm{~Hz}$ and then filtered with a 4th order Butterworth filter with a low pass cutoff at $10 \mathrm{~Hz}$. Accelerometer data were streamed wirelessly at
Table 2 Biomechanical variable definitions

\begin{tabular}{|c|c|c|}
\hline Abbreviation & Explanation & $\begin{array}{l}\text { Measurement } \\
\text { convention }\end{array}$ \\
\hline Hip-max & $\begin{array}{l}\text { Maximum hip angle } \\
\text { (before foot-strike). }\end{array}$ & Positive $=$ flexion \\
\hline Hip-FS & Hip angle at foot-strike. & \\
\hline Hip-MS & Hip angle at mid-stance. & \\
\hline Нiр-ТO & Hip angle at toe-off. & \\
\hline Knee-FS & Knee angle at foot-strike. & Positive $=$ flexion \\
\hline Knee-MS & Knee angle at mid-stance. & \\
\hline Knee-TO & Knee angle at toe-off. & \\
\hline Ankle-FS & Ankle angle at foot-strike. & Positive $=$ dorsiflexion \\
\hline Ankle-TO & Ankle angle at toe-off. & \\
\hline $\mathrm{PR}$ & $\begin{array}{l}\text { Mean range of pelvis rotation } \\
\text { in the transverse plane for } \\
\text { each gait cycle. }\end{array}$ & Scalar \\
\hline FA & $\begin{array}{l}\text { Foot advance; sagittal plane } \\
\text { distance between the heel } \\
\text { and COM at foot contact, } \\
\text { relative to mean leg length. }\end{array}$ & Scalar \\
\hline DROP & $\begin{array}{l}\text { Vertical displacement of COM } \\
\text { from foot contact to mid-stance, } \\
\text { relative to mean leg length. }\end{array}$ & Scalar \\
\hline RISE & $\begin{array}{l}\text { Vertical displacement of COM } \\
\text { from mid-stance to toe-off, } \\
\text { relative to mean leg length. }\end{array}$ & Scalar \\
\hline$S R$ & Step rate. & Steps per min \\
\hline
\end{tabular}

$617 \mathrm{~Hz}$ to Agilelink software (Microstrain, Williston, VT), subsequently re-sampled at $200 \mathrm{~Hz}$, and filtered similarly to correspond with motion capture data. During running, the device is not perfectly aligned relative to the room (i.e., the global coordinate system, as opposed to the body coordinate system). Corrections were made for the tilt of the accelerometer, based on the method of Moe-Nilssen [9]. We provide a brief description of the calculations, but we encourage the reader to study the details provided in that paper [9]. Correction is possible because the mean vector angles in the ML and AP sensing axes may be estimated while the participant is running (see Appendix for calculations). The RMS of the vertical $\left(\mathrm{VT}_{\mathrm{RMS}}\right)$, medio-lateral $\left(\mathrm{ML}_{\mathrm{RMS}}\right)$, and anterior-posterior $\left(\mathrm{AP}_{\mathrm{RMS}}\right)$ axes was then calculated for the epochs in each trial:

$$
x_{R M S}=\sqrt{\frac{1}{N} \sum_{i}^{N} x_{i}{ }^{2}}
$$

where $x$ is the given plane and $N$ is the total number of samples in $60 \mathrm{sec}$ (at $200 \mathrm{~Hz}, N=12,000$ ). The resultant Euclidian scalar variable (RES) was also calculated 
for the determination of the magnitude of the overall body acceleration:

$$
R E S_{R M S}=\sqrt{V T_{R M S}^{2}+M L_{R M S}^{2}+A P_{R M S}^{2}}
$$

The above processing and analysis of data was done using custom designed code in a Matlab environment (Matlab R2013b, Mathworks, Natick, MA).

\section{Statistical tests}

Correlations were first performed to assess the relationship between anthropometric variables and acceleration. Analysis of variance (ANOVA) was used to determine the effect of speed on the four acceleration and fourteen biomechanical variables. A stepwise regression was then used to determine the significant kinematic contributions to acceleration in each axis. We also performed principal component analysis (PCA) to reduce the dimensionality of the data into significant components using a varimax rotation and Kaiser normalization. A stepwise regression was then performed using these components as predictors of acceleration in each axis. Post hoc power analyses were conducted for all ANOVA and regression analyses. A Bonferroni test was used for multiple comparisons, where appropriate. Statistical significance was set at $\mathrm{p}<0.05$. Statistical analysis was done using SPSS software (version 21, IBM Corporation, Armonk, NY).

\section{Results}

Significant speed effects were found for RMS-accelerations for ML, AP, and RES $(\mathrm{p}<0.05$, Table 3$)$. Of the biomechanical variables, only maximum hip angle showed a significant speed effect ( $\mathrm{p}<0.05$, Table 3). Height, mass, and BMI were not significantly correlated with acceleration in any axis $(\mathrm{p}<0.05)$.

Regression indicated 4 to 5 significant variables associated with acceleration, depending on the axis (Table 4). We encourage the reader to take notice of the sign of the beta coefficients (Table 4) and the angle definitions (Table 2) to understand the direction of change that is associated with an increase in acceleration. The combination of significant variables was different for each axis. Explained variance $\left(\mathrm{R}^{2}\right)$ ranged from 0.71 to 0.82 . A plot of predicted versus measured RMS acceleration for each axis is provided in Figure 1.

PCA indicated 4 significant kinematic components (Table 5), explaining $79.1 \%$ of total variance. Component $1(\lambda=4.9,37.4 \%$ of variance) was comprised of variables predominantly associated with hip flexion in late flight and early stance phase (hip-MS, hip-FS, knee-MS, hip$\max )$. Component $2(\lambda=2.8,21.2 \%$ of variance) was associated with the propulsive phase of the gait cycle (ankle-TO, knee-TO, RISE, PR). Component $3(\lambda=1.6$, $12.5 \%$ of variance) included variables associated with
Table 3 Mean (SD) acceleration and biomechanical variables for each speed

\begin{tabular}{|c|c|c|c|c|}
\hline \multirow[t]{2}{*}{ Variable } & \multicolumn{3}{|c|}{ Speed $(\mathrm{m} / \mathrm{s})$} & \multirow{2}{*}{$\begin{array}{c}\text { Observed } \\
\text { power }\end{array}$} \\
\hline & 2.22 & 2.78 & 3.33 & \\
\hline$\overline{M L_{\text {RMS }}(g)^{*}}$ & $0.35(0.05)$ & $0.41(0.06)^{\dagger}$ & $0.46(0.07)^{\dagger}$ & 1.00 \\
\hline $\operatorname{AP} P_{\text {RMS }}(g)^{*}$ & $0.36(0.06)$ & $0.43(0.10)^{\dagger}$ & $0.50(0.10)^{\dagger}$ & 0.99 \\
\hline $\mathrm{VT}_{\mathrm{RMS}}(\mathrm{g})$ & $1.09(0.13)$ & $1.18(0.11)$ & $1.19(0.10)$ & 0.72 \\
\hline $\operatorname{RES}_{\text {RMS }}(g)^{*}$ & $1.21(0.12)$ & $1.33(0.12)^{\dagger}$ & $1.38(0.11)^{\dagger}$ & 0.99 \\
\hline Hip-max (deg)* & $36.2(6.8)$ & $42.1(7.2)^{\dagger}$ & $48.3(7.4)^{\dagger}$ & 1.00 \\
\hline Hip-FS (deg) & $28.9(6.5)$ & $31.5(5.8)$ & $34.6(6.2)$ & 0.68 \\
\hline Hip-MS (deg) & $22.6(7.6)$ & $24.9(6.9)$ & $27.6(7.4)$ & 0.41 \\
\hline Hip-TO (deg) & $-5.4(5.6)$ & $-8.4(5.6)$ & $-10.5(5.6)$ & 0.68 \\
\hline Knee-FS (deg) & $13.0(8.2)$ & $12.3(6.6)$ & $13.7(6.6)$ & 0.08 \\
\hline Knee-MS (deg) & $37.9(7.1)$ & $39.3(6.8)$ & $40.6(6.7)$ & 0.16 \\
\hline Knee-TO (deg) & $10.5(6.5)$ & $8.6(5.8)$ & $8.0(6.1)$ & 0.19 \\
\hline Ankle-FS (deg) & $9.4(5.0)$ & $8.9(4.8)$ & $9.2(4.8)$ & 0.06 \\
\hline Ankle-TO (deg) & $-11.5(7.5)$ & $-16.0(5.4)$ & $-17.6(5.7)$ & 0.76 \\
\hline PR (deg) & $3.9(1.6)$ & $4.7(2.5)$ & $5.6(3.7)$ & 0.34 \\
\hline $\begin{array}{l}\text { FA (\% mean } \\
\text { leg length) }\end{array}$ & $5.3(2.9)$ & $6.9(3.0)$ & $9.2(3.8)$ & 0.90 \\
\hline $\begin{array}{l}\text { DROP (\% mean } \\
\text { leg length) }\end{array}$ & $6.2(1.7)$ & $6.3(1.5)$ & $5.9(1.4)$ & 0.10 \\
\hline $\begin{array}{l}\text { RISE (\% mean } \\
\text { leg length) }\end{array}$ & $8.6(1.7)$ & $8.9(1.5)$ & $8.7(1.5)$ & 0.09 \\
\hline SR (steps/min) & $155.5(9.5)$ & $158.0(9.0)$ & $163.1(10.5)$ & 0.54 \\
\hline
\end{tabular}

*Significant speed effect at $\mathrm{p}<0.05,{ }^{\dagger}$ significantly different from $2.22 \mathrm{~m} \cdot \mathrm{s}^{-1}$.

cushioning during the early stance phase (knee-FS, DROP, ankle-FS). Regressions (Table 6) indicated that components 1 and 2 significantly predicted ML, VT, and RES acceleration $\left(R^{2}\right.$ from 0.32 to $\left.0.40, p<0.001\right)$. Component 3 significantly predicted AP acceleration $\left(R^{2}=\right.$ $0.041, \mathrm{p}=0.041$.

\section{Discussion}

The purpose of this study was to determine the biomechanical contributors to global axial RMS accelerations during running. We found significant relationships where explained variance using regressions on the original variables was 0.71 for ML, 0.53 for AP, 0.74 for VT, and 0.43 for RES. PCA did identify hidden relationships that explained $79 \%$ of the variance of the original variables and that were not evident using only multiple regression. When regressions were performed using the PCA component variables, though, explained variance was lower than with the original biomechanical variables alone. Reducing the numerous variables into a few principal components therefore does explain much of the variance in a simplified manner, but the predictive value of this simplified relationship is not as strong as using a traditional regression with a non-reduced variable set. 
Table 4 Regression results for original variables

\begin{tabular}{|c|c|c|c|c|c|}
\hline Dependent & Adjusted $\mathrm{R}^{2}$ & Independent & Beta & $p$ & $\begin{array}{c}\text { Observed } \\
\text { power }\end{array}$ \\
\hline \multirow[t]{4}{*}{$\overline{M L_{R M S}}$} & $0.714^{a}$ & Hip-max & 0.009 & $<0.001$ & 1.00 \\
\hline & & Hip-TO & -0.005 & $<0.001$ & \\
\hline & & Knee-FS & -0.003 & 0.002 & \\
\hline & & Knee-MS & -0.003 & 0.020 & \\
\hline \multirow[t]{5}{*}{$\overline{A P_{R M S}}$} & $0.718^{b}$ & Hip-max & 0.016 & $<0.001$ & 1.00 \\
\hline & & Hip-MS & -0.010 & $<0.001$ & \\
\hline & & Нiр-ТO & -0.008 & $<0.001$ & \\
\hline & & FA & -0.010 & $<0.001$ & \\
\hline & & RISE & -0.020 & 0.001 & \\
\hline \multirow[t]{5}{*}{$\overline{\mathrm{VT}_{\mathrm{RMS}}}$} & $0.795^{c}$ & Hip-FS & 0.034 & $<0.001$ & 1.00 \\
\hline & & FA & -0.027 & $<0.001$ & \\
\hline & & Hip-MS & -0.030 & $<0.001$ & \\
\hline & & Hip-max & 0.010 & $<0.001$ & \\
\hline & & Ankle-TO & -0.014 & $<0.001$ & \\
\hline \multirow[t]{5}{*}{$\overline{\mathrm{RES}_{\mathrm{RMS}}}$} & $0.822^{d}$ & Hip-Max & 0.017 & $<0.001$ & 1.00 \\
\hline & & FA & -0.028 & $<0.001$ & \\
\hline & & Hip-FS & 0.034 & $<0.001$ & \\
\hline & & Hip-MS & -0.036 & $<0.001$ & \\
\hline & & Ankle-TO & -0.014 & $<0.001$ & \\
\hline
\end{tabular}

${ }^{\mathrm{a}} \mathrm{F}(4,51)=35.362, \mathrm{p}<0.001 ;{ }^{\mathrm{b}} \mathrm{F}(5,50)=28.960, \mathrm{p}<0.001 ;{ }^{\mathrm{C}} \mathrm{F}(5,50)=45.542$, $p<0.001 .{ }^{d} R E S: F(5,50)=51.967, p<0.001$.

Accelerations measured at the lumbar spine originate from the GRF, which is transmitted through the foot, shank, thigh, and pelvis. GRF at the shank is typically biphasic and is significantly attenuated at proximal body segments $[20,21]$. The two GRF peaks are associated with impact and propulsion [22,23], with resultant body segment acceleration depending on GRF magnitude and damping effects [24]. The magnitude of force applied to the ground depends, in part, on the stiffness of the lower extremities, as does the acceleration resulting from the GRF.

According to the regressions, increased RMS accelerations were associated with different combinations of the following kinematic characteristics during early stance phase, depending on the axis: increased hip flexion, decreased knee flexion, and decreased foot advance. Most studies demonstrate that a combination of increased hip flexion and decreased ankle dorsiflexion at foot contact is associated with alterations in GRF during foot contact in various settings, providing evidence for the role of both the quadriceps and the ankle dorsiflexor muscles in shock absorption [25-30]. Our data did not demonstrate the importance of ankle dynamics in shock attenuation, but did highlight the role of hip angle in positioning the quadriceps for shock attenuation during running [21,31]. Indeed, decreased FA was associated with increased AP,
VT, and RES acceleration. In contrast, a greater FA leads to a flatter angle of attack (i.e., angle between segment and the ground), which results in high lengthening rates and decreased rate and magnitude of loading [32].

During the late stance and propulsion phase, a greater hip extension and ankle plantar flexion at toe off were associated with greater RMS acceleration. According to modeling by Hamner et al. [30], the soleus and gastrocnemius provide the biggest contributions to the propulsion phase. Data from the present study supports the important role of the ankle plantar flexors in propulsion.

Kinematic observations in the current study are similar to changes observed by McMahon et al. [16] when performing a "Groucho running" intervention. In that study, reductions in leg stiffness were associated with reduced GRF and increased metabolic cost and are accomplished by increased knee flexion. In contrast, in the present study this appears to be facilitated by increased hip joint excursion and a decreased foot advance. We note that Groucho running is an exaggerated style for the purpose of establishing a relationship, and not intended for exercise and performance purposes. The subjects in the present study used a freely-chosen technique and were not given any instruction to modify their form. Still, the kinematic descriptions we provide would seem to be subject to modification with skill training $[17,18]$.

There is also evidence that the level of acceleration may be modified with training. We have previously shown that the vertical accelerations of trained collegiate runners are lower than untrained individuals but greater than triathletes with similar fitness and training volume [33]. This may represent an optimization of the different performance requirements and injury risk between the different groups because the optimal magnitude of vertical accelerations for performance may be different than what is optimal for minimizing risk of injury, and both may be different from sport to sport. Acceleration magnitude and stiffness may reflect several aspects of physical function during running such as energy expenditure, impact forces relating to stress and injury, and performance $[10,11]$. Often, one aspect must be compromised if another is to be maximized. For example, high impact forces accompanying high limb stiffness may increase energy return and performance according to the springmass model but may require more energy and occur at the expense of an overuse injury [32].

In the current study, we employ a simple approach to modeling, including kinematic descriptions and a single acceleration quantity for each axis (representing accelerations over the entire gait cycle); this work represents an easily accessible method with the potential for real-time output. Although it is not possible to fully account for the myriad of interactions between force, acceleration, stiffness, effective segmental mass, performance, and injury, 

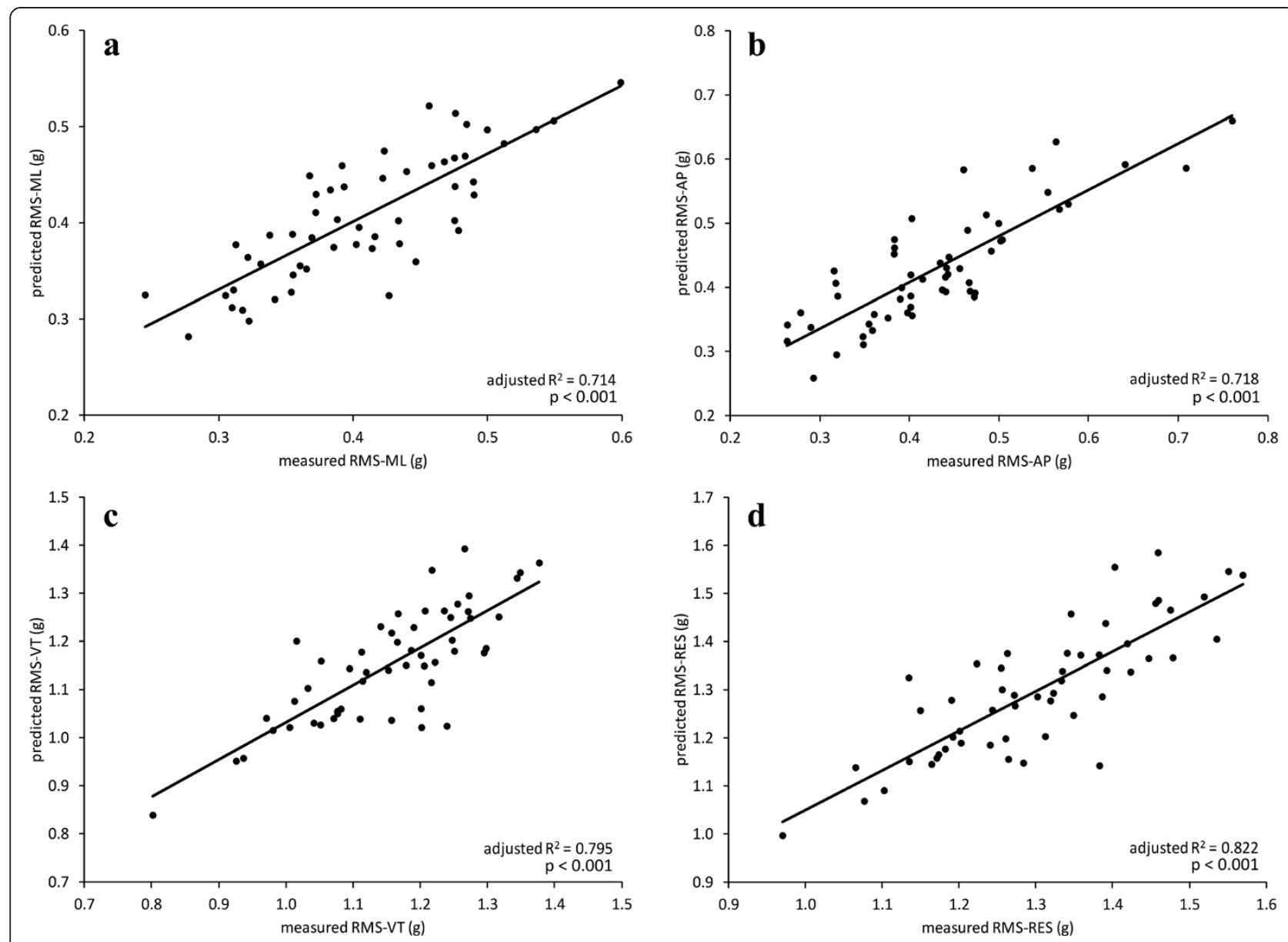

Figure 1 Predicted RMS acceleration versus measured RMS acceleration values. Graphs indicate: (a) ML, b) AP, c) VT, and d) RES.

Each graph includes data from all three speeds. Most biomechanical variables did not show a speed effect.

Table 5 Rotated component matrix from principal component analysis

\begin{tabular}{lcccc}
\hline & \multicolumn{4}{c}{ Component } \\
\cline { 2 - 5 } & $\mathbf{1}$ & $\mathbf{2}$ & $\mathbf{3}$ & $\mathbf{4}$ \\
\hline Hip-MS & $\mathbf{0 . 9 1 0 ^ { * }}$ & -0.058 & 0.081 & -0.127 \\
Hip-FS & $\mathbf{0 . 9 0 6 ^ { * }}$ & 0.022 & -0.016 & 0.134 \\
Knee-MS & $\mathbf{0 . 8 9 7 ^ { * }}$ & 0.034 & 0.239 & 0.213 \\
Hip-max & $\mathbf{0 . 8 5 2 ^ { * }}$ & -0.146 & 0.157 & 0.105 \\
Ankle-TO & -0.114 & $\mathbf{0 . 8 8 8 ^ { * }}$ & -0.033 & -0.295 \\
Knee-TO & 0.345 & $\mathbf{0 . 8 1 2 ^ { * }}$ & 0.076 & 0.069 \\
RISE & 0.599 & $-\mathbf{0 . 6 5 8 ^ { * }}$ & -0.063 & -0.009 \\
PR & 0.172 & $-\mathbf{0 . 5 1 7}$ & -0.054 & -0.122 \\
Knee-FS & 0.342 & -0.004 & $\mathbf{0 . 9 0 2 *}$ & -0.074 \\
DROP & 0.600 & -0.006 & $-\mathbf{0 . 6 6 7 *}$ & 0.243 \\
Ankle-FS & 0.505 & 0.305 & $\mathbf{0 . 5 1 4}$ & 0.117 \\
FA & 0.352 & 0.062 & -0.172 & $\mathbf{0 . 8 1 0 ^ { * }}$ \\
Hip-TO & 0.401 & 0.588 & -0.112 & $-\mathbf{0 . 5 9 1 *}$ \\
\hline B &
\end{tabular}

Bold font and *indicates grouping for each component. there have been several reports of the benefits of interventions using acceleration as an outcome variable $[17,18,34]$. Data reduction via PCA facilitates the tracking of such characteristics because the number of features becomes relatively smaller [35]. Indeed, satisfactory descriptions of walking gait using PCA ( $80-90 \%$ explained variance)

Table 6 Regression results for principal components

\begin{tabular}{lccccc}
\hline Dependent & Adjusted R & Predictors & Beta & $\boldsymbol{p}$ & $\begin{array}{c}\text { Observed } \\
\text { power }\end{array}$ \\
\hline ML $_{\text {RMS }}$ & $0.322^{\mathrm{a}}$ & Component 1 & 0.418 & $<0.001$ & 1.00 \\
& & Component 2 & -0.415 & $<0.001$ & \\
$\mathrm{AP}_{\text {RMS }}$ & $0.058^{\mathrm{b}}$ & Component 3 & 0.273 & 0.041 & 1.00 \\
$\mathrm{VT}_{\mathrm{RMS}}$ & $0.401^{\mathrm{c}}$ & Component 2 & -0.529 & $<0.001$ & 1.00 \\
& & Component 1 & 0.378 & 0.001 & \\
$\mathrm{RES}_{\text {RMS }}$ & $0.380^{\mathrm{d}}$ & Component 2 & -0.513 & $<0.001$ & 1.00 \\
& & Component 1 & 0.374 & 0.001 & \\
\hline
\end{tabular}

${ }^{a} F(2,53)=14.066, p<0.001 ;{ }^{b} F(1,54)=4.364, p=0.041 ;{ }^{C} F(2,53)=19.412, p<0.001$. ${ }^{d} F(2,53)=17.875, p<0.001$. 
applied to continuous waveforms of joint markers or joint ankles have been obtained with only the first three or four principal components [35-39]. However, sometimes only one of many principal components is significantly different between subject groups (fallers vs. non-fallers, overweight vs. normal weight) or experimental conditions (loaded vs. non-loaded) in walking tasks [40,41]. The reduction of the kinematic variables into four principal components may aid conceptualization of the key gait characteristics that contribute to the magnitude of accelerations. That it was possible to form components from the different biomechanical variables is likely indicative of movement synergies employed by the individual as a motor strategy [37]. To the extent that this strategy can be altered, this presents an opportunity to modify force production and impact absorption.

The discrete values used in the present study represent an a priori reduction from continuous waveform data, and may be seen as a limitation, but the maximum and minimum values found in a waveform can often be the regions of most significant difference [40], and would thus likely be captured at points during the gait cycle that we examined. As well, the complete dataset of biomechanical variables displayed greater explained variance than the principal components. This may indicate that the reduction of the complete dataset results in the loss of important information that is explanatory with regard to gait dynamics. However, this does not necessarily diminish the value in identifying otherwise hidden synergistic relationships perhaps indicative of a neuromuscular strategy. Another limitation is the small number of biomechanical variables chosen for analysis. While the selection of a few readily modifiable variables provides a simple preliminary analysis, there are other variables that have not been included that potentially affect RMS trunk acceleration. Indeed, our measurements focused on movement in the sagittal plane, but this neglects frontal plane dynamics that may influence medio-lateral acceleration. Because the accelerometer only approximates COM movement, the findings are limited if an explanation of COM per se is desired. However, if the goal is to investigate what contributes to measured accelerations, and explain previous findings (c.f. McGregor [8]) then the factors highlighted in this paper provide a basis for future investigations.

\section{Conclusions}

This study helps to establish the use of lumbarmounted accelerometers to demonstrate effects related to stiffness, impact, and the attenuation of acceleration. Previous work has demonstrated the connection between RMS accelerations and energy expenditure [8]. Our present data provides a more mechanistic explanation of how various kinematic configurations may influence the multi-segmental force cascade from the foot-ground interface to the lumbar vertebrae where accelerations are measured. Specifically, we have identified the role of hip and knee angles in shock absorption and the role of the hip and ankle in propulsion. In addition to establishing these key biomechanical contributors to acceleration, we showed how many of these variables change in concert. Wherever these variables are modifiable, the acceleration signal may be a useful way to monitor movement with a view to performance and injury management. Our findings pertain to young, healthy, and active men and women, but the relationships found here can form the basis from which more specific subject groups may be studied in the future.

\section{Appendix}

\section{Statistical tests}

The following steps and equations are based on MoeNilssen [9]. For a dataset of large N, the acceleration vector approaches the sine of the angle of that vector:

$$
\begin{aligned}
& \lim \bar{a}_{M L}=\sin \theta_{M L} \\
& \lim \bar{a}_{A P}=\sin \theta_{A P}
\end{aligned}
$$

The coordinate system definitions must be strictly maintained so that the positive/negative signs are correct and the relationships hold true. The following corrections were applied to each of the axes:

$$
\begin{aligned}
& a_{A \text { Pcorr }}=a_{A \text { Pmeas }} \cdot \cos \theta_{A P}-a_{V \text { TMeas }} \cdot \sin \theta_{A P} \\
& a_{V \text { Tprov }}=a_{A \text { Pmeas }} \cdot \sin \theta_{A P}+a_{V \text { Tmeas }} \cdot \cos \theta_{A P} \\
& a_{\text {MLcorr }}=a_{\text {MLmeas }} \cdot \cos \theta_{M L}-a_{V \text { Tprov }} \cdot \sin \theta_{M L} \\
& a_{V \text { Tcorr }}=a_{\text {MLmeas }} \cdot \sin \theta_{M L}+a_{V \text { Tprov }} \cdot \cos \theta_{M L}+1
\end{aligned}
$$

where corr, meas, and prov refer to corrected, measured, and provisional terms, respectively. The static component of gravity was also corrected for the VT axis, leaving only the dynamic acceleration component.

\section{Competing interests}

The authors declare that they have no competing interests.

\section{Authors' contributions}

TL participated in study design, carried out data collection, performed data processing, and drafted the manuscript. JY participated in interpretation of data and drafting the manuscript. SM conceived of the study, performed statistical analysis, participated in interpretation of data and drafting of the manuscript. All authors read and approved the final manuscript.

\section{Acknowledgements}

The authors are thankful to the subjects and for data collection assistance from Aaron Stickel, Lucas Wall, Zach Maino, Ken Hayes, and Ann Brennan.

\section{Author details}

${ }^{1}$ School of Health Promotion \& Human Performance, Eastern Michigan University, Ypsilanti, MI, USA. ${ }^{2}$ School of Health Sciences \& Human

Performance, Ithaca College, Ithaca, NY, USA. 
Received: 2 May 2013 Accepted: 20 November 2014

Published: 12 December 2014

\section{References}

1. Sport Business Research Network. [http://www.sbrnet.com/research.asp? subRID=512]

2. Van Gent RN, Siem D, van Middelkoop M, van Os AG, Bierma-Zeinstra SMA, Koes BW: Incidence and determinants of lower extremity running injuries in long distance runners: a systematic review. Br J Sports Med 2007, 41:469-480.

3. Ghani Zadeh Hesar N, Van Ginckel A, Cools A, Peersman W, Roosen P, De Clercq D, Witvrouw E: A prospective study on gait-related intrinsic risk factors for lower leg overuse injuries. Br J Sports Med 2009, 43:1057-1061.

4. Hreljac A: Etiology, prevention, and early intervention of overuse injuries in runners: a biomechanical perspective. Phys Med Rehabil Clin N Am 2005, 16:651-667.

5. Messier SP, Legault C, Schoenlank CR, Newman JJ, Martin DF, DeVita P: Risk factors and mechanisms of knee injury in runners. Med Sci Sports Exerc 2008, 40:1873-1879.

6. Niemuth PE, Johnson RJ, Myers MJ, Thieman TJ: Hip muscle weakness and overuse injuries in recreational runners. Clin J Sport Med 2005, 15:14-21.

7. Almeida SA, Williams KM, Shaffer RA, Brodine SK, Sandra A, Maxwell K, Richard A, Stephanie K: Epidemiological patterns of musculoskeletal injuries and physical training. Med Sci Sports Exerc 1999, 31:1176-1182.

8. McGregor SJ, Busa MA, Yaggie JA, Bollt EM: High resolution MEMS accelerometers to estimate $\mathrm{VO} 2$ and compare running mechanics between highly trained inter-collegiate and untrained runners. PLOS ONE 2009, 4:e7355.

9. Moe-Nilssen R: A new method for evaluating motor control in gait under real-life environmental conditions. Part 1: the instrument. Clin Biomech 1998, 13:320-327.

10. Butler RJ, Crowell HP, Davis IM: Lower extremity stiffness: implications for performance and injury. Clin Biomech 2003, 18:511-517.

11. Derrick TR: The effects of knee contact angle on impact forces and accelerations. Med Sci Sports Exerc 2004, 36:832-837.

12. Busa MA, Muth T, Herman C, Hornyak J, Bollt EM, Mcgregor SJ: High resolution accelerometry can identify changes in running dynamics across an inter-collegiate cross country season [abstract]. Med Sci Sports Exerc 2010, 42(Suppl 5):91.

13. Latash ML, Zatsiorsky VM: Joint stiffness: myth or reality? Hum Mov Sci 1993, 12:653-692.

14. Zhang S, Bates BT, Dufek JS: Contributions of lower extremity joints to energy dissipation during landings. Med Sci Sports Exerc 2000, 32:812-819.

15. Devita P, Skelly WA: Effect of landing stiffness on joint kinetics and energetics in the lower extremity. Med Sci Sports Exerc 1992, 24:108-115.

16. McMahon TA, Valiant G, Frederick EC: Groucho running. J Appl Physiol 1987, 62:2326-2337.

17. Crowell HP, Davis IS: Gait retraining to reduce lower extremity loading in runners. Clin Biomech 2011, 26:78-83.

18. Crowell HP, Milner CE, Hamill J, Davis IS: Reducing impact loading during running with the use of real-time visual feedback. J Orthop Sports Phys Ther 2010, 40:206-213.

19. Fellin RE, Rose WC, Royer TD, Davis IS: Comparison of methods for kinematic identification of footstrike and toe-off during overground and treadmill running. J Sci Med Sport 2010, 13:646-650.

20. Mercer JA, Vance J, Hreljac A, Hamill J: Relationship between shock attenuation and stride length during running at different velocities. Eur J Appl Physiol 2002, 87:403-408.

21. Derrick TR, Hamill J, Caldwell GE, Graham E: Energy absorption of impacts during running at various stride lengths. Med Sci Sports Exerc 1998, 30:128-135.

22. Novacheck T: The biomechanics of running. Gait Posture 1998, 7:77-95

23. Munro CF, Miller DI, Fuglevand AJ: Ground reaction forces in running: a reexamination. J Biomech 1987, 20:147-155.

24. Lafortune MA, Lake MJ, Hennig E: Transfer function between tibial acceleration and ground reaction force. J Biomech 1995, 28:113-117.

25. Madigan ML, Pidcoe PE: Changes in landing biomechanics during a fatiguing landing activity. J Electromyogr Kinesiol 2003, 13:491-498.

26. Christina K, White S, Gilchrist L: Effect of localized muscle fatigue on vertical ground reaction forces and ankle joint motion during running. Hum Mov Sci 2001, 20:257-276.
27. Gerritsen GM, van den Bogert AJ, Nigg BM, Gerritsen KG: Direct dynamics simulation of the impact phase in heel-toe running. J Biomech 1995, 28:661-668

28. Kim W, Voloshin AS, Johnson SH: Modeling of heel strike transients during running. Hum Mov Sci 1994, 13:221-244.

29. Bobbert MF, Schamhardt HC, Nigg BM: Calculation of vertical ground reaction force estimates during running from positional data. J Biomech 1991, 24:1095-1105.

30. Hamner SR, Seth A, Delp SL: Muscle contributions to propulsion and support during running. J Biomech 2010, 43:2709-2716.

31. Keller TS, Weisberger AM, Ray JL, Hasan SS, Shiavi RG, Spengler DM: Relationship between vertical ground reaction force and speed during walking, slow jogging, and running. Clin Biomech 1996, 11:253-259.

32. Seyfarth A, Geyer H, Günther M, Blickhan R: A movement criterion for running. J Biomech 2002, 35:649-655.

33. Maino ZJ, Gordon JP, Workman AD, Daoud A, McGregor SJ: Differences in running mechanics and economy between collegiate runners and triathletes identified using high-resolution accelerometers [abstract]. Med Sci Sports Exerc 2011, 43(Suppl 5):105.

34. Davis IS: Gait retraining in runners. Orthop Pract 2005, 17:8-13.

35. Daffertshofer A, Lamoth CJC, Meijer OG, Beek PJ: PCA in studying coordination and variability: a tutorial. Clin Biomech 2004, 19:415-428.

36. Milovanović I, Popović DB: Principal component analysis of gait kinematics data in acute and chronic stroke patients. Comput Math Methods Med 2012, 2012:649743.

37. Mah CD, Hulliger M, Lee RG, O'Callaghan IS: Quantitative analysis of human movement synergies: constructive pattern analysis for gait. J Mot Behav 1994, 26:83-102

38. Dillmann U, Holzhoffer C, Johann Y, Bechtel S, Gräber S, Massing C, Spiegel J, Behnke S, Bürmann J, Louis AK: Principal component analysis of gait in Parkinson's disease: relevance of gait velocity. Gait Posture 2014, 39:882-887.

39. Troje NF: Decomposing biological motion: a framework for analysis and synthesis of human gait patterns. J Vis 2002, 2:371-387.

40. Lee M, Roan M, Smith B: An application of principal component analysis for lower body kinematics between loaded and unloaded walking. J Biomech 2009, 42:2226-2230.

41. Kobayashi $Y$, Hobara H, Matsushita S, Mochimaru M: Key joint kinematic characteristics of the gait of fallers identified by principal component analysis. J Biomech 2014, 47:2424-2429.

doi:10.1186/1743-0003-11-162

Cite this article as: Lindsay et al:: Contributions of lower extremity kinematics to trunk accelerations during moderate treadmill running. Journal of NeuroEngineering and Rehabilitation 2014 11:162.

\section{Submit your next manuscript to BioMed Central and take full advantage of:}

- Convenient online submission

- Thorough peer review

- No space constraints or color figure charges

- Immediate publication on acceptance

- Inclusion in PubMed, CAS, Scopus and Google Scholar

- Research which is freely available for redistribution 